\title{
IS KNOWLEDGE OF A NON-DOMINANT L2 ACTIVATED BY BILINGUALS USING THEIR DOMINANT L1? INSIGHTS FROM AN ON-LINE PSYCHOLINGUISTIC STUDY
}

\author{
Ricardo Augusto de Souza (UFMG) \\ Fernando Luiz Pereira de Oliveira (UFOP)
}

\begin{abstract}
L1 influences on L2 learning and use are phenomena vastly documented in L2 learning research (ODLIN, 1989; JARVIS \& PAVLENKO, 2007). However, approaches to the inversed phenomenon, i.e.: L2 influences on L1, are more recent (COOK, 2003). Studies of L2 effects on the L1 tend to examine bilinguals living in the linguistic environments of the L2. In the present study, we report the results of a psycholinguistic study that suggests that bilinguals who probably have their L1 as the dominant language may nonetheless activate L2 semantics-syntax interface representations over the course of sentence processing. We discuss our results with respect to their implications for the cognitive architecture of bilinguals' language representations, as well as what they might signify for language contact situations.
\end{abstract}

Key words: Sentence processing, argument structure, L2 effects on L1. 1- INTRODUCTION

Bilingualism studies largely suggest that the linguistic systems of a bilingual do not function separately (cf. HERNÁNDEZ, FERNÁNDEZ and AZNAR-BESÉ, 2007 for a review of relevant research). Indeed, Organon, Porto Alegre, nº 51, julho-dezembro, 2011, p. 103-128 
psycholinguistic studies of bilingual language processing can be viewed as majorly concerned with providing models to account for how two or more languages are represented, activated and interrelated in an individual's mind. The view of a reasonably shared cognitive architecture for the organization of bilinguals' languages is well aligned with the very much studied phenomenon of L1 influences on L2 representations obtained especially by late bilinguals over the course of second language acquisition (cf. ODLIN, 1989; and JARVIS and PAVLENKO, 2007 for extensive reviews). However, an important corollary of models that claim for shared linguistic representations is the possibility that not only the L 2 is influenced by knowledge of the L1, but that the L1 may be also influenced by knowledge of an L2.

Systematic studies of L2 influences on the L1 are a much more recent research enterprise (cf. PAVLENKO and JARVIS, 2002; COOK, 2003). A majority of such studies branch from the school of investigations on language attrition phenomena. As stated by Köpke and Schmid (2004), although at its birth the field of language attrition studies concentrated on loss of language abilities in either L1 or L2, as of the last decade of the last century the area has concentrated mostly on the investigation of possible loss of different aspects of an L1 as a result of extensive and prolonged bilingualism, usually focusing on bilinguals whose linguistic environment is no longer that of the L1. Indeed, studies of L2 effects on the $\mathrm{L} 1$ tend to look at language experiences and language processing data from bilinguals whose levels of second language proficiency and linguistic histories are suggestive of potential dominance inversions between the $\mathrm{L} 1$ and the $\mathrm{L} 2{ }^{1}$.

The present study also sought to explore the possibility of L2 influ-

1 In this paper we use the labels L1(first language) and L2 (second language) as explicit descriptors of order of acquisition. It should be highlighted that the language first acquired by a bilingual is not necessarily his or her dominant language, understood as the language most frequently activated for use. Dominance inversion may be the norm among bilinguals who started acquiring their L2 at a very young age because of immigration (cf. FERNÁNDEZ, 2003). In this paper we adopt a simplified notion of dominance, construed after the fact that our subjects were bilingual residents of a L1-speaking society. However, Grosjean (2008, pp. 22-26) discusses evidence in support of his "Complementarity principle", in which he proposes that dominance may actually be domain specific, in other words, a bilingual may have Lx as the dominant language for a given domain of social practices, such as his or her professional life, and Ly as the dominant language for another domain, such as participation in religious groups. Notwithstanding, in view of the nature of the empirical investigation we will report, we do not believe that an evaluation of domain-bound language practices would be critically important. 
ences on the L1. We took knowledge of an L2 as a significant source of representations that feeds the overall cognitive architecture that supports language processing. In other words, our guiding hypothesis is that for bilinguals L2 representations are in tandem with L1 representations when semantic and syntactic organization is built onto the incoming linguistic signals during language comprehension. However, we took a different line of inquiry for the present study with respect to the fact that we explored the possibility that processing effects of the L2 on the L1 can be obtained among bilinguals who have not necessarily undergone language dominance inversion.

In the present investigation the view of bilingualism suggested by Grosjean (2008) is adopted. According to Grosjean, the bilingual individual is not necessarily a person equally competent in both languages. A bilingual person is understood to be an individual who functions in two or more languages according to specific communicative needs and opportunities offered by the environment, and who consequently may stand at quite different levels of competence in one of the languages he or she uses at a given point in time.

Also, in the present study we addressed the activation of linguistic representations in the bilingual mind by examining grammatical phenomena that can be modeled as reflecting mappings of semantic configurations onto syntactic structure, specifically, matters of argument structure realization. Our choice for this particular set of phenomena was motivated by the fact that there is ample evidence in second language research attesting that $\mathrm{L} 2$ realization of argument structure is a domain of linguistic structure especially liable to cross-linguistic influences. L1 influences on L2 argument structure realization has been examined with respect to both availability of grammatical representations in interlanguages and their use in real time language processing (cf. JUFFS, 1998; MONTRUL, 1998; MONTRUL, 2001, WHITE, 2003).

In the remainder of this article, a section will be dedicated to the exploration of argument structure realization as grammatical phenomena and its role in models of language processing. It will be followed by a section specifically dedicated to the type of construction examined in our study, and to earlier findings about its impact on the linguistic representations of Brazilian Portuguese-English bilinguals to which the present study aims to be a supplement. The following sections will de-

Organon, Porto Alegre, nº 51, julho-dezembro, 2011, p. 103-128 
tail the methodology of our study, as well as its results and their discussion. The article finishes with a conclusion that attempts at suggesting new venues of exploration that could depart from our findings.

\section{2- ARGUMENT STRUCTURE IN GRAMMAR AND IN SENTENCE PROCESSING}

Sentences depict some sort of event or state in the real world or in imagined worlds. Such depictions will establish relationships of entities and circumstances, and also relationships of entities with one another. Sentences can be understood as the linguistic expression of those conceptual relationships, and therefore they must codify the roles semantically attributed to the entities referred to by the lexical items that shape them up. Languages may differ concerning the structural devices they

offer their speakers for such codification. Both English and Portuguese are examples of languages that rely on sentence word order as a way to encode semantic roles in the lexical items referring to the entities participating of events. This can be easily verified in sentences (1) and (2) below, examples of active voice sentences, and rough translations of each other:

(1) Bill kicked the ball.

(2) O Guilherme chutou a bola.

The event depicted by both sentences can be schematically described as one that involves an agent and a patient, and word order seems to be an important parameter for the establishment of "Bill" and "Guilherme" as agents, as well as "the ball" and "a bola" as patients. It is true, however, that word order alone is not the only reliable parameter involved in the construal of the event depicted by those sentences. Indeed, both English and Portuguese speakers have structural alternatives to this sentence - which could be chosen because of pragmatic or discourse motivations, for instance - that would render the referents of the words "Bill", "Guilherme", "ball", and "bola" the same agent and patient roles, even though the order of such words would be reversed. These structural alternatives are instantiated in (3) and (4) below, passive voice sentences:

(3) The ball was kicked by Bill.

(4) A bola foi chutada pelo Guilherme.

Indeed, word order can be regarded as a by-product of semantic 
specifications that are intimately related to the meaning associated with the verbs of the four sentences above. Word order is not actually the single structural device for the expression of argument realization, as there are languages in which morphology plays the key role. Constraints imposed through semantic specifications are captured by the very label "agent", which implies an entity capable of volition and action, in other words, an entity construed as a living being. Thus, when uttering sentences such as (1) and (2) above, speakers of English and Portuguese have grammars that provide them with a linking algorithm that makes the entity qualifying semantically as agent (i.e., a living entity) be mapped onto the syntactic subject ${ }^{2}$. That such linking algorithm is verb-dependent, or more specifically dependent on verb meanings, can be testified in the following English sentences3:

(5) Jimmy feared thunderstorms.

(6) Thunderstorms frightened Jimmy.

(7) ${ }^{\star}$ ?? Thunderstorms feared Jimmy.

(8) */?? Jimmy frightened thunderstorms.

The case illustrated in sentences (5) to (8) represents a noteworthy example of specialized linking algorithms. Both the psych-verb "fear" and the psych-verb "frighten" entail conceptual representations that could be roughly paraphrased as "cause to be afraid". Nevertheless, "fear" renders an algorithm linking the semantic experiencer - necessarily an entity construed as capable of experiencing psychological states - to the grammatical subject, and it also links the cause of that psychological state to the grammatical object. The verb "frighten" renders precisely the opposite linking algorithm. Sentences (7) and (8) above are ungrammatical or at least highly anomalous because the entities referred to by respectively the grammatical subject and the grammatical object fail to match the semantic configuration specified by the verbs and their linking algorithms, namely, being an entity to which psychological states are attributed ${ }^{4}$.

2 For a model of how verb meanings may specify - or subcategorize - semantic roles, and of how these roles are mapped to grammatical role categories (such as subject, object and oblique), see Culicover (2009).

3 Throughout the remainder of our exposition of sentences to illustrate linguistic arguments, we will employ the following stigmata: An $\left(^{*}\right)$ means ungrammaticality, (??) mean semantic anomaly, and (\%) means acceptable for speakers of certain varieties.

4 It should also be mentioned that verbs are not the only argument selecting grammatical category. Adjectives too select arguments. An interesting case of morphological expression of

Organon, Porto Alegre, nº 51, julho-dezembro, 2011, p. 103-128 
The set of linguistic phenomena described above, involving relationships between the semantics of specific verbs and verb types, and how in event construal they link to noun phrases at certain syntactic positions - or arguments - are under the scope of what is described as argument realization (cf. LEVIN \& RAPPAPORT-HOVAV, 2005). Argument realization patterns are language-specific mappings of conceptual configurations of events onto morpho-syntactic structures. As pointed out by Levin and Rappaport-Hovav (2005), among others, argument structure realization varies greatly from language to language. Also, argument realization is a fundamental mechanism of verbal predication, a claim that can be confirmed by the observation of how central a role models of argument structure play in theories of the overall architecture of grammatical knowledge (cf. CHOMSKY, 1981; VAN VALIN \& LAPOLA, 1995; GOLDBERG, 1995; JACKENDOFF, 2002).

Not only are matters of argument structure and argument realization relevant to the theory of grammar, but it is also suggested that they are also significant in mechanisms of sentence processing. A proposal that knowledge of argument structure is activated for language performance is found in Levelt's (1989) model of speech production. In Levelt's model, a message is built up in a "conceptualizer" as propositional content, and the output of the conceptualizer is the input of a "formulator", where concepts are translated into linguistic units. According to Levelt (1989, p. 88), the hierarchical nature of the semantic relations of a given conceptualized message leads to the assumption that "the Formulator should ideally 'know' what kinds of syntactic constituents to develop for all parts of the message". Consequently, Levelt's model predicts that argument structure (thematic structure in his terminology) shapes the construction of utterances at a stage of their mental organization that precedes their mapping onto morphophonemic units.

Argument structure is not only relevant for a model of speech pro-

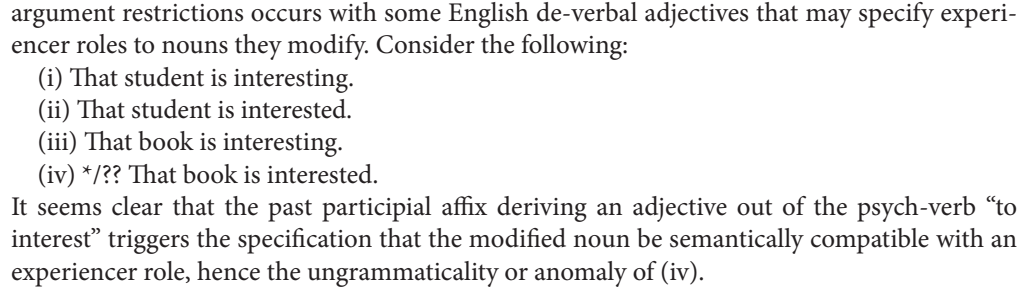


duction such as Levelt's, though. Empirical evidence supporting that semantic role specifications and argument structure realization are relevant factors guiding sentence comprehension has also been found in psycholinguistic research. Truswell, Tanenhaus \& Garnsey (1994), for instance, challenged previously proposed views that animaticity - a semantic feature associated with noun referents - played little if any role in early disambiguation of reduced passive relative clauses. Results of one of the eye-tracking experiments reported in Truswell, Tanenhaus \& Garnsey (1994) indicate that semantic constraints had clear effects on temporary ambiguity resolution (p. 298). Thus, a noun semantically underspecified for an agent role required by the argument structure of the verb, such as the first head noun in "The evidence examined by the lawyer turned out to be unreliable", from Truswell, Tanenhaus \& Garnsey's study, provides the reader/listener with early evidence for the passivized reduced relative clause reading. The same evidence is unavailable in the first noun of "The defendant examined by the lawyer turned out to be unreliable" (also from the authors' study), as it is semantically fully specified for either agent or patient roles.

Effects of verb argument structure on sentence processing were also found in Boland, Tanenhaus \& Garnsey (1995). In a self-paced reading and "make-sense" judgment study exploring the processing of gap-filler dependencies, the authors examined factors affecting the plausibility of Wh-dependencies in such a way that their experimental sentences would support sense-bearing readings. By way of five experiments, Boland, Tanenhaus \& Garnsey (1995) provide evidence that although readers have a general "bias to interpret a filler as the direct object of a potentially transitive main verb" (p. 798), when a verb's argument structure allows for multiple gap sites, the semantic fit of the filler mediates this general bias. Therefore, Boland, Tanenhaus \& Garnsey's study also suggest that semantic information associated with the realization of argument structure is employed in the incremental interpretation of sentences. $^{5}$

5 Much of the research work aligned with the findings in Truswell, Tanenhaus \& Garnsey (1994) and Boland, Tanenhaus \& Garnsey (1995) is construed as support of a non-serial view of sentence processing, especially perspectives that challenge syntax-driven models. Counter-arguments concerning non-serial models are found in Clifton, Jr. et al. (2003). We do not judge our methodology sufficient to enable us to take positions with respect to whether the architecture of sentence processing is serial or not, neither do we find a solution to this relevant theoretical 
It seems clear that knowledge of argument realization patterns is a major component of knowledge of grammar, and that such knowledge is activated at early stages of sentence processing, feeding the parser in the online establishment of structure for sound or grapheme strings. Because those patterns tend to be distinctively language-specific, it is plausible to expect that over L2 development bilinguals face the task of reconfiguring L1 patterns of argument realization whenever they divert from the L2 grammar. In the next section, this proposal will be further explored with respect to how Brazilian Portuguese-English bilinguals cope with verbs of manner of motion, a class of verbs with argument realization viabilities in English that do not seem to match the argument structure licensed by the equivalent verb class in Portuguese.

\section{3- INDUCED ACTION PREDICATES}

Levin (1993) describes a peculiar argument structure behavior that occurs with a set of English verbs expressing different manners of motion. Such set of verbs include items like run, fly, jump, race, etc, and are referred to by the author as run-verbs. The peculiarity of the manner-of-motion verbs of English with respect to argument structure realization results from the fact that these verbs may alternate between a single-argument - or intransitive - behavior and a two-argument - i.e., transitive - behavior.

When producing mono-argumental predicates, run-verbs are normally agentive, and the semantic reading that stems from a sentence with an instance of run-verb as predicator can be schematically represented as " $[\{\mathrm{x}-$ agent $\}$ event $]$ ". When manner-of-motion verbs produce double-argument predicates, Levin (1993) describes the resulting construction as entailing a causative connotation. Consequently, the alternative bi-argumental syntactic configuration where run-verbs are licensed maps onto a semantic reading that can be represented as " $[\{\mathrm{x}$ - causer $\}$ cause $\{y$ - agent $\}$ event]”. According to Levin (1983), the double-argument constructions with run-verbs require adjunct prepositional phrases to be fully licensed. The phenomena described by Levin

problem of crucial importance in face of the goals of the present study. What we do consider highly relevant to our study is the evidence that argument structure information affects on-

line sentence processing at a stage before a mental representation of the complete sentence is achieved. 
for run-verbs in English are illustrated in sentences (9) to (14) below, in which march and run are predicators.

(9) The soldiers marched.

(10) The rat ran.

(11) ?? The captain marched the soldiers.

(12) ?? The psychologists ran the rat.

(13) The captain marched the soldiers to the tents.

(14) The psychologists ran the rat through the maze.

From the vantage point of speakers of Brazilian Portuguese, the behavior of English manner-of-motion verbs can be regarded as especially peculiar, as although occurrences of transitivity alternations entailing causative connotations are found in that language (cf. SILVA, 2009) ${ }^{6}$, they do not seem to apply across the board to the equivalent run-verbs in Portuguese as a coherent set. This fact is illustrated in sentences (15) to (18), among which sentences (17) and (18) are judged as either ungrammatical or highly anomalous:

(15) Os soldados marcharam.

(16) As cobaias correram.

(17) */?? O capitão marchou os soldados para o acampamento.

(18)*/?? Os psicólogos correram o rato pelo labirinto.

The claim that induced-action constructions with run-verbs are productive in English but restricted in Brazilian Portuguese is supported by Souza (forthcoming) in an empirical study with English and Brazilian Portuguese monolinguals and Brazilian Portuguese (L1)-English (L2) bilinguals. In that offline acceptability judgment study, Souza analyzed judgments made by self-declared monolinguals of Brazilian Portuguese reading sentences in Portuguese that mimicked the English inducedaction run-verb predicates (such as "Os psicólogos correram o rato pelo labirinto [The psychologists ran the rat through the maze]"), as well as English-speaking and bilingual Portuguese-English subjects at two levels

6 An interesting example of one such occurrence is illustrated in sentence (iii) below, which is acceptable for speakers of some regional varieties of Brazilian Portuguese, such as dialects spoken in the state of Minas Gerais, (cf. Silva 2009, p. 108), but which is certainly ungrammatical in English, as stated in (iv):

(i) Joana almoçou.

(ii) Joana lunched.

(iii) \% Joana almoçou seus filhos mais cedo hoje.

(iv) * Joana lunched her kids earlier today (meaning "Joana made her kids lunch earlier today). 
of proficiency in English L2 reading such predicates instantiated by sentences in English. Souza's study examined five English run-verbs occurring in both make-causatives (i.e., "The psychologists made the rat run through the maze") and induced-action constructions and their equivalent Portuguese counterparts in make-causatives and mimicry induced action constructions. The verbs were run, march, jump, walk, and fly.

The results reported in Souza (forthcoming) indicated that the Brazilian Portuguese-speaking monolinguals had a clear, well-established tendency to reject acceptability for the mimicking induced-action construction in Portuguese with all five verbs except "pular" (the equivalent of jump). This behavior was in sharp contrast with the generally high acceptability shown by the English speaking subjects when judging the English equivalent sentences. The results with the bilingual subject pool revealed a significant contrast related to proficiency level in the L2. On the one hand, the Brazilian Portuguese-English L2 bilingual subjects with lower L2 proficiency levels tended to judge the English sentences as unacceptable to a degree that made them and the Brazilian Portuguese monolingual pool be undifferentiated groups in relation to most verbs. On the other hand, the Brazilian Portuguese-English L2 bilingual subjects with higher L2 proficiency levels tended to judge the induced-action constructions as acceptable, contrasting with the behavior of both lower-proficiency bilinguals and Brazilian Portuguese monolinguals, and making them undifferentiated from the English subject pool in their ratings of induced-action run-verbs.

Souza (forthcoming) interpreted his results as empirical support to the claim that run-verbs as a class licensing causative meaning twoargument syntax does not exist in the grammar possessed by speakers of Brazilian Portuguese. The results were also taken as evidence that the induced action behavior of run-verbs in English is acquired by Brazilian Portuguese-English L2 bilinguals at advanced levels of proficiency. Finally, these results were taken as strongly suggestive of L1 influences on the L2 of the bilingual subjects at lower proficiency in the L2, as the L1 grammar seems to constrain the acceptability of a licensed structure in the L2, deeming it underrepresented in the interlanguage grammar of those subjects. On the other hand, the high proficiency bilingual pool in Souza's study seems to have successfully departed from the restriction apparently imposed by their L1 grammar.

The findings in Souza (forthcoming) were taken as clear enough to 
motivate an exploration tackling whether or not L2 influences on L1 processing of the induced-action predicate could result from the departure of the L1 grammar associated with higher levels of competence in the L2. To investigate this question, an on-line study ${ }^{7}$ was designed. The methods employed in the on-line study, and the analyses of data it produced are discussed in the next two sections.

\section{4- METHOD AND RESULTS}

The on-line study reported here employed a self-paced moving window reading paradigm. In this paradigm, subjects are asked to perform a reading task in which they need to read a sequence of sentences. During the experimental task, each sentence is first presented as a series of dash segments. Those segments are substituted one at a time by the word strings that compose a given sentence in response to the participants' activation of a specific key in a controlling device. In other words, the sentences are segmented, and segments are displayed one at a time as a response to a command sent by the reader, who therefore controls the pace of his or her own reading of each of the sentences. Reaction times (RTs) are measured as participating subjects move along the sentence fragments. Such measures are indicators of the relative cognitive burden imposed by the contents of each fragment as they become visible to subjects and are therefore incrementally integrated with the linguistic material being processed (cf. MITCHELL, 2004).

As discussed in further details below, the on-line study reported here was designed primarily in order to enable estimates of the relative impact of presentation of noun phrased whose interpretation depended on their integration as direct objects of the preceding verb. The subjects' profiles, materials and data collection procedures will be presented separately below.

7 Psycholinguistic methods for the study of language processing may be broadly referred to as off-line and on-line. Off-line methods - of which grammaticality judgments are one common example in the study of reactions to sentences- delve into the effects of language processing rather than processing itself, as they tackle behavior that requires a linguistic representation to have been formed. On-line methods, on the other hand, try to capture information related to the on-going development of linguistic representations. On-line methods are exemplified by procedures such as the one described in the next section for the study of sentence processing, in which the goal is to assess the processing cost, inferred by differences in reaction time, of the construction of a sentential representation. For details about off-line methods in psycholinguistic studies of language processing, we recommend Derwing \& de Almeida (2005). For an overview of on-line methods, we recommend Mitchell (2004).

Organon, Porto Alegre, nº 51, julho-dezembro, 2011, p. 103-128 


\section{1- Subjects}

Twenty-seven subjects took part in the present study. The subjects were all above 18 years-old, and all of them had at least college entry-level education at the time of the study. Participants' gender was not controlled for, and both males and females participated. All of the subjects were native speakers of Brazilian Portuguese. Two thirds of them considered themselves bilinguals in Brazilian Portuguese and English at some level of proficiency in English L2, and the remaining third declared not to be users of English or of any language other than Brazilian Portuguese. Because all bilingual subjects of the present study were long-term residents in Brazil when data was collected, there is a high probability that Brazilian Portuguese was the dominant language of all of them.

The participants of the study were divided into three groups of 9 subjects each. Each group was assigned to a different experimental condition with respect to the language involved in the experimental task, as described in the "materials" sub-section. These three groups are defined as a "monolingual" group who read sentences in Portuguese, as a "bilinguals reading sentences in Portuguese" group, and a "bilinguals reading sentences in English" group.

For the assignment of subjects into the three groups, the linguistic profile was the single most important participant variable controlled for in the study. In order to achieve such control, prospective subjects first responded to a questionnaire in which they stated their self-perceived level of competence in spoken and written English in a five-point scale ranging from very little command to full command in four language skills (reading, writing, oral comprehension and speaking). Participants also provided information about the amount of time for which they had perceived themselves as users of English L2 to accomplish activities of their interest, and the amount of time passed since they started learning English.

Potential subjects who declared having little command in three of the four language skills, as well as who did not consider themselves as users of English L2 to accomplish activities of their interest were automatically assigned to the "monolingual" group for the purposes of this study. Subjects who declared having full command in at least three of the four skills and who had proof of using English for professional reasons on a daily basis for ten years or more were automatically assigned to the "bilinguals reading sentences in Portuguese" group. All 
other subjects indicating an overall high level of command of oral and/ or written skills in English were submitted to a test of English vocabulary (Nation, 1990), which ranks subjects in a five-band scale representing estimates of their lexicon in English. Subjects who were placed in Bands 4 or 5, which represent mastery of a college level vocabulary in English, were randomly assigned to either the "bilinguals reading sentences in Portuguese" group or the "bilinguals reading sentences in English" group. Therefore, all the subjects of the present study were either Brazilian Portuguese-English L2 bilinguals at a high proficiency level as attested by their linguistic profile questionnaires and/or vocabulary test, or subjects failing to perceive themselves as users of English as a non-native language.

\section{2- Materials}

The self-paced moving window reading task involved two sets of 31 sentences each, one set in English and another containing equivalent sentences in Portuguese. Seven sentences in the English set instantiated different run-verbs in the induced action construction. By the same token, the Portuguese set had seven sentences with the Portuguese equivalent of the seven run-verbs in constructions mimicking the induced action predicates of English. The remaining 24 sentences of each of the two sets were fillers. Except for the seven sentences in Portuguese mimicking induced action constructions, none of the sentences were designed to contain any sort of ungrammaticality. All sentences were followed by YES-NO comprehension questions.

The seven target sentences of both English and Portuguese sets were controlled for overall syntax, some semantic properties, and phonological structure, especially at the critical points of measurement, namely the verb and the second noun phrase. With respect to syntax, the seven English sentences were of the type $\mathrm{NP}_{1}-\mathrm{V}-\mathrm{NP}_{2}-\mathrm{PP}$, with PPs configured as a Head Preposition followed by an NP. Therefore, the seven target sentences contained three NPs each, summing up 21 noun phrases. All 21 noun phrases instantiated the structure Det-Head Noun, and the definite article the was determiner in all of them. All verbs were inflected for past tense. Hence, from a semantic point of view all English sentences suggested a perfective aspect event, involving specific entities. With respect to the phonological structure of the verb and the second noun phrase, all English verbs were monosyllables, and all second

Organon, Porto Alegre, nº 51, julho-dezembro, 2011, p. 103-128 
noun phrases formed a disyllabic phonological word with the definite article and the head noun. Together with the verb that preceded each of them, the second noun phrase of the target sentences added up to three syllables in the English target sentences.

The seven Portuguese target sentences instantiated the same syntactic arrangement of their English counterparts. However, not all verbs used in the set can be said to be literal translations of the English counterparts, as the attempt at naturalness in combination of potential agent of movement and manner-of-motion verb ranked as higher a priority than strict equivalence of lexeme meaning across both languages. Neither did the second noun phrases in the Portuguese set instantiate overt determiners. Those that did not have overt determiners displayed surface bare head nouns in plural form, thus not entailing the reading of a specific entity, but rather a generic one. This change in the semantic and syntactic parameter at this critical point of measurement resulted from phonological control ranking as higher a priority than syntactic and semantic control. All second noun phrases in the Portuguese sentences had three syllables, and together with the verbs that preceded them could add up a total ranging from five to six syllables. A deliberate option was made to keep the number of syllables at these critical regions to a minimum, avoiding further departure from the three syllables of the English version, as a guarantee that RT differences would not be badly affected by blatant differences of phonological structure across data sets. This choice was made at the cost of strict semantic and syntactic convergence between Portuguese and English sentences. Figure 1 displays the seven target English and Portuguese sentences:

English induced action sentences
The researchers ran the mice through the maze.
The soldiers raced their tanks down the street.
The policemen walked their dogs to the house.
The surfers swam the whales beyond the waves.
The farmer leaped the pony over the pond.
The scientists flew balloons above the clouds.
The trainer jumped the lion through a hoop.
Portuguese mimicry induced action sentences
O pesquisador correu cobaias em um labirinto.
Os soldados andaram os tanques pela rua.
Os policiais caminharam cachorros para a casa.
Os surfistas nadaram golfinhos para alto mar.
O fazendeiro saltou o pônei sobre o fosso
Os cientistas voaram os balões para cima das nuvens.
O treinador pulou o leão através do círculo.

Figure 1- Target sentences in English and in Portuguese. 
All target sentences and fillers in both sets were followed by YES and NO questions focusing on inferences based on the propositional content of the sentences. These questions were designed to be mostly simple and easy to answer. The primary goal of the questions was to maintain subjects' attention to the content of the sentences at a level high enough to guarantee that processing of the linguistic material was taking place during task performance. "Did the researchers run?" and "O pesquisador correu?" are examples of questions, and they followed the sentences "The researchers ran the mice through the maze" and "O pesquisador correu cobaias em um labirinto", in the English and in the Portuguese sets, respectively. The answers to the YES and NO questions were ignored, thus not being analyzed in this study. The main reason for not taking the answers to questions into account over analysis is the fact that most questions did not necessarily converge towards an either absolutely right or absolutely wrong answer . $^{8}$

All sentences in the two sets were segmented and presented in four chunks. In the target sentences, the first chunk corresponded to the first $\mathrm{NP}$, the second to the inflected word form of the head verb, the third to the second NP, and the last to the PP. In all fillers the first chunk was a NP and the second to an inflected word form of a verb lexeme. The segmentation of the sentences "The scientists flew balloons above the clouds" and "Os cientistas voaram os balões para cima das nuvens" was therefore "The scientists / flew / balloons / above the clouds" and "Os cientistas / voaram / os balões / para cima das nuvens".

The self-paced reading task was produced and presented for performance through a DMDX script. DMDX also provided the records of participants' RTs. Subjects manipulated a computer gamepad in order to pass through the sentence chunks, to see the comprehension question for each sentence and provide a YES or NO answer. Performance of the task was done at an IBM-type computer. The ensuing statistical analyses were performed using the Minitab version 15 software.

8 This lack of convergence is exemplified in the following two pairs of sentence-question, the first a target sentence, and the second a filler sentence:

SENTENCE: The surfers swam the whales beyond the waves; QUESTION: Were there whales in the sea?

SENTENCE: The coach told the players to jog around the field. QUESTION: Did the coach jog around the field?

Organon, Porto Alegre, nº 51, julho-dezembro, 2011, p. 103-128 


\section{3- Procedures}

Participants were informed that they would perform a sentence comprehension task in which questions followed sentences, and once a sentence had been read there would be no possibility of returning to it in order to check information for answers. All subjects performed the self-paced reading task in a quiet room furnished with two desks and equipped with three computers, one of which was assigned specifically for the task. This room was located on the campus of a university in Brazil. For each experimental session, subjects entered the room in company of an experimenter, who introduced the subjects to the interface for the task and to the gamepad and the commands used to pass through sentence segments and to supply the YES or NO response to the comprehension questions.

Once introduced to the computer interface and gamepad functions, subjects had training sessions with example sentences and questions. During the training sessions, the participants were accompanied by the experimenter, who checked the subjects understanding of all procedures. At the end of each training session, the experimenter had a final check of whether the subjects had any questions or doubts about what they were expected to do in the self-paced reading task, and if subjects were confident about what they had to do, the experimenter left the room asking them to only start the real task once alone in the room. Subjects performed the task all alone in the room, behind closed doors. Experimental sessions lasted about ten minutes.

\section{4- Analyses}

The critical data for this study were measures of RTs - in milliseconds - when readers encountered the second noun phrase in the target sentences of each set. The key assumption was that in the absence of activation of a grammatical representation that renders such noun phrases semantically interpretable, readers would take longer to pass through the third segment of the target sentences. The attempt at integrating the second noun phrase into the string of words being processed would lead readers who fail to activate a grammatical base to support such integration to at least temporarily lose automaticity of response, and thus be compelled to delay their reaction to move on through the sentence in several milliseconds.

Organon, Porto Alegre, nº 51, julho-dezembro, 2011, p. 103-128 
This analytical framework provided a yardstick to further explore the results previously found by Souza (forthcoming) about monolingual speakers of Portuguese rejecting the acceptability of induced action predicates. As Souza's previous study employed an offline measure (sentence judgments), it is possible that the behaviors observed reflected metalinguistic assessments of the sentence type that took place several seconds after successful processing of the linguistic data. In such case, the claim for underrepresentation of manner-of-motion verbs as a class licensing induced action predicates in Brazilian Portuguese L1 would be put into question. The judgments reported in Souza's study might reflect, for instance, the fact that the construction is sociolinguistically marked to the point of being denied acceptability by speakers of the language, despite being fully interpreted over the course of sentence processing ${ }^{9}$.

Furthermore, the analytical framework and the design of the present study allow for tackling the issue of how separated or how integrated the two languages of bilinguals are. If the processing of the second noun phrase in the segmented sentences resulted in different behaviors in connection to the language of the input, this would be a strong indicator that manner-of-motion verbs in induced action predicates are not only English-specific, but will trigger more automatized responses from bilinguals only if the right language is at use. In such case, a significant level of linguistic separation could be claimed for.

In summary, the specific hypotheses guiding this study can be paraphrased as a null hypothesis and two alternative hypotheses:

$\mathrm{H}_{0}$ : The "monolinguals", the "bilinguals reading sentences in Portuguese", and the "bilinguals reading sentences in English" are not different groups with respect to their reactions to the second noun phrase of the induced action sentences. In other words, the constructions are equally costly irrespective of language of expression of the text and of the language profile of the reader.

$\mathrm{H}_{\mathrm{A} 1}$ : The "bilinguals reading sentences in English" form a group pro-

9 This would be a highly plausible explanation to Souza's (forthcoming) results for monolinguals, as the subjects had at least college-entry level of education and could therefore make sharp distinctions about forms considered higher and lower Portuguese. If this were the case, the differences across less proficient bilinguals and high proficiency bilinguals also found in that study could be explained as the result of a reconfiguration of the sociopragmatic marking speakers of Brazilian Portuguese would attribute to the construction over the course of their English L2 development.

Organon, Porto Alegre, nº 51, julho-dezembro, 2011, p. 103-128 
cessing the critical region faster than both "monolinguals" and the "bilinguals reading sentences in Portuguese". In other words, the assumed language-specificity of the induced action predicate holds true, and knowledge of L2 English does not affect processing of the Portuguese mimic sentences.

$\mathrm{H}_{\mathrm{A} 2}$ : Both the "bilinguals reading sentences in English" and the "bilinguals reading sentences in Portuguese" form groups processing the critical region faster than "monolinguals". In other words, the assumed language-specificity of the induced action predicate holds true, and knowledge of L2 English does affect processing of the Portuguese mimic sentences.

Two statistical tests were employed in the exploration of these hypotheses. The reason for the dual test choice is the fact that when there is access to data from a given random variable $\mathrm{X}$ in which the probability distribution in the population is unknown, as was the case of this study, it is necessary to identify the probability distribution that best fits the experimental data. Identification of probability distributions is relevant, as depending on the distribution that best fits the data set choices concerning which inferential procedures will be applied may vary. In this study the Anderson-Darling (Stephens, 1974) test was employed. This test examines whether a data sample comes from a population with specific distributions. For the present study, tests were conducted to verify whether the data came from a normally distributed population. Testing our data set with the Anderson-Darling procedure revealed that for some of the verb-second noun positions explored, a normal distribution was obtained for the samples, whereas for others it was not. The normally distributed samples were tested with T-tests of two independent samples, and the non-normally distributed samples were tested with Wilcoxon-Mann-Whitney, a test fitting non-parametric data ${ }^{10}$.

We did not reject the null hypothesis $\left(H_{0}\right)$, and we accepted the bilingual groups' similarity if $\mathrm{p}$-values are greater than or equal to a significance level ( $\alpha$ ). For this study an $\alpha$-level of 0.05 was used across all statistical tests.

For this study an $a$-level of 0.05 was used across all statistical tests.

10 In t-tests group means are analyzed, whereas in the Wicoxon-Mann-Whitney test, medians are analyzed. For detailed discussions of the Wicoxon-Mann-Whitney test, see Wilcoxon (1945), and Mann and Whitney (1947). 


\section{5- Results}

As previously stated, the critical analysis in the present study is the cognitive cost for processing the third fragment (second noun phrase) of the target sentences, measured as the amount of time a reader would spend as he or she passed through those noun phrases. Figure 2 presents seven graphics, one for each second noun phrase pair as they appeared to readers in each target sentence of the two language sets. The graphics in Figure 2 identify the reader groups (bilingual versus monolingual) and the language presented in the self-paced reading task (either English for one of the bilingual groups, or Portuguese for the other bilingual group and the monolingual group). They also identify the mean amount of time (measured in milliseconds) spent by each group at the second noun phrase window of the self-paced reading interface. Finally, the column graphics show the standard error range marked in each column.

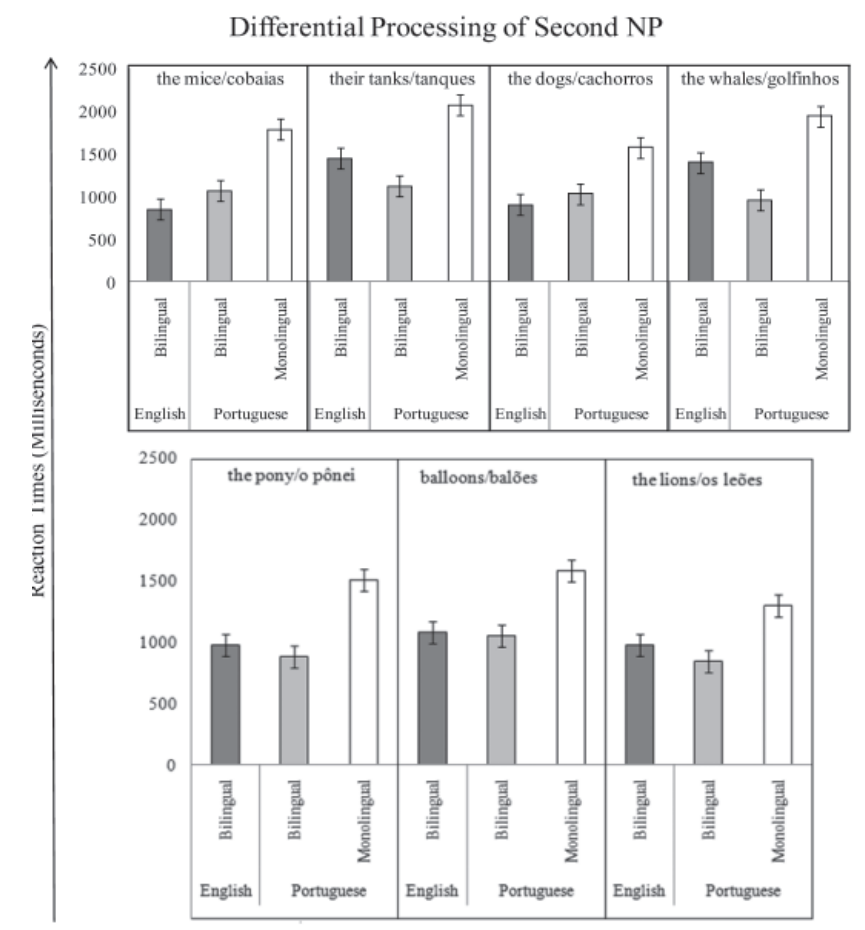

Figure 2 - Comparisons of the second NP processing of bilinguals reading in L1 (Brazilian Portuguese) or L2 (English) versus monolingual reading in Brazilian Portuguese.

Organon, Porto Alegre, nº 51, julho-dezembro, 2011, p. 103-128 
As can be viewed in Figure 2, monolingual subjects reading the Portuguese mimic induced action sentences with manner-of-motion verbs systematically spent more time passing through the second noun phrase of each of the target sentences. Also, it can be seen that the RTs of bilingual subjects reading the same predicate type in English generally tended to approximate those of the bilingual subjects reading the Portuguese mimic counterparts. It is noteworthy that the mean RTs of bilingual subjects reading in Portuguese were actually slightly smaller than those of the bilingual subjects reading in English for five of the seven critical positions of the target sentences. This reduced mean reaction time can be tentatively explained as an effect of Portuguese probably being the dominant language of all bilingual subjects of this study.

The results of the statistical tests employed in this study to verify whether the differences identified for the three subject groups would lead to the rejection of the null hypothesis $\left(H_{0}\right)$ are summarized in Tables 1 and 2.

Table 1 - T-test for the equality of means ( $\alpha$-level $=0.05$ )

\begin{tabular}{|c|c|c|c|c|c|}
\hline Noun phrases & Groups & Estimate for difference & $\mathrm{t}$ & $\mathrm{df}$ & Sig. (2-tailed) \\
\hline $\begin{array}{l}\text { Noun phrase - the } \\
\text { mice/cobaias }\end{array}$ & Bil $_{\text {Eng }} \times$ Bil $_{\text {Port }}$ & -216 & -1.23 & 11 & 0.243 \\
\hline \multirow{3}{*}{$\begin{array}{l}\text { Noun phrase - their } \\
\text { tanks/tanques }\end{array}$} & Mono X Bil Eng & -754 & $-2,49$ & 15 & $0.025^{*}$ \\
\hline & Mono X Bil Port & -1076 & $-4,27$ & 14 & $0.001^{*}$ \\
\hline & Bil $_{\text {Eng }} \times$ Bil $_{\text {Port }}$ & 322 & 1,22 & 13 & 0.245 \\
\hline $\begin{array}{l}\text { Noun phrase - their dogs/ } \\
\text { cachorros }\end{array}$ & Mono X Bil ${ }_{\text {Port }}$ & -737 & $-2,67$ & 10 & $0.024^{*}$ \\
\hline \multirow[t]{2}{*}{$\begin{array}{l}\text { Noun phrase - the } \\
\text { whales/golfinhos }\end{array}$} & Mono X Bil ${ }_{\text {Port }}$ & -1021 & $-3,76$ & 13 & $0.002^{*}$ \\
\hline & Mono X Bil $F n \sigma$ & -618 & $-2,91$ & 13 & $0.012^{*}$ \\
\hline
\end{tabular}

Table 2 - Mann-Whitney test for the equality of median ( $\alpha$-level $=0.05$ )

\begin{tabular}{|c|c|c|c|}
\hline Noun phrases & Groups & Statistic W & Test is significant at \\
\hline \multirow{2}{*}{ Noun phrase - the mice/cobaias } & Mono X Bil Eng & 54 & $0,0062^{*}$ \\
\hline & Mono X Bil ${ }_{\text {port }}$ & 56 & $0,0104 *$ \\
\hline \multirow{2}{*}{ Noun phrase - their dogs/ cachorros } & Mono X Bil Eng & 60 & $0,0273^{*}$ \\
\hline & Bil $_{\text {Eng }} \times$ Bil $_{\text {Port }}$ & 69 & 0,1577 \\
\hline \multirow{2}{*}{ Noun phrase - the whales/golfinhos } & Mono X Bil Eng & 63 & 0,0521 \\
\hline & Bil $_{\text {Eng }} \times$ Bil ${ }_{\text {Port }}$ & 100 & 0,2164 \\
\hline \multirow{3}{*}{ Noun phrase - the lion/ o leão } & Mono X Bil Eng & 56 & $0,0104^{*}$ \\
\hline & Mono X Bil ${ }_{\text {Port }}$ & 45 & $0,0004^{*}$ \\
\hline & Bil $_{\text {Eng }} \times$ Bil $\left.\right|_{\text {Port }}$ & 79 & 0,5962 \\
\hline
\end{tabular}

${ }^{*}$ p-value $<0.05$ 
As can be seen in the tables, the null hypothesis $\left(H_{0}\right)$ is rejected when the RTs at the critical position of the target sentence of the monolinguals are compared with bilinguals reading both in Portuguese L1 and English L2. In other words, when presented to the noun phrase that followed a manner-of-motion verb, Brazilian Portuguese speaking readers with too little knowledge of English faced a systematically higher processing cost than individuals of the same linguistic background when reading equivalent linguistic input in either their L1 or their L2. The tables also reveal very relevant information about what happened to both bilingual groups: the null hypothesis $\left(H_{0}\right)$ is not rejected when their RTs at the second noun phrase are compared. In other words, irrespective of the generally smaller mean reaction times of the bilinguals reading in their L1 in most of the target sentences, the two groups cannot be distinguished with respect to the processing cost of the induced action predicate with manner-of-motion verbs whether the input is in L2 English or L1 Portuguese. The second alternative hypothesis, claiming that the language-specificity of the induced action predicate holds true, and knowledge of L2 English does affect processing of the Portuguese mimic sentences, is therefore accepted after the empirical data found in the present study.

\section{5-DISCUSSION}

The results of the present study contribute to the line of enquiry of a previous study of induced action predicates with manner-of-motion verbs reported in Souza (forthcoming) in respect to the confirmation that such predicates form a linguistic contrast between Brazilian Portuguese and English. Whereas the previous study revealed a tendency for rejection of this predicate type by monolinguals and bilinguals at lower proficiency levels in sentence acceptability judgments, the present study supplements those findings by providing empirical evidence that such rejections correspond to higher processing costs of this construction for individuals whose active grammatical representations follow the grammar of Portuguese. We assume that the present findings illuminate those reported in Souza (forthcoming) by exploring a methodology that allows for claims that the sentence judgment results

observed were not limited to a by-product of metalinguistic evaluations

Organon, Porto Alegre, nº 51, julho-dezembro, 2011, p. 103-128 
of the appropriateness of the construction as a standard form. In view of the present results, the poor judgments obtained in that study can be interpreted as at least in part stemming from the reduced processability of run-verb induced action predicates to early stage Brazilian Portuguese L1 speakers of English L2.

Far more important than the run-verb induced action construction itself, however, is what this class of constructions may reveal about how bilinguals manage knowledge of their two languages over the course of language learning and language use. Results of the present study provide an interesting indication that a language-specific representation - the causative NP-V-NP-PP construction - was active over the incremental building of a sentence structure by bilinguals of L1 Brazilian Portuguese and L2 English when they processed input in Portuguese. The availability of such representation explains the augmented speed of their processing of the Portuguese mimic sentences, as it accounts for generalized automaticity of integration of a noun phrase as direct object of a manner-ofmotion verb at subliminal stages of sentence comprehension.

These findings apparently mitigate assumptions that L2 effects on the L1 sentential structure are consequences of dominance inversion alone. As stated above, all subjects of this study were long-term residents of Brazil, and the study itself took place in a Portuguese-speaking setting in Brazil. Therefore, although the bilingual subjects were all of a high proficiency level in their L2, they could barely be described as having an overall inverted dominance of L1 and L2. Our results are convergent with those by Hartsuiker, Pickering and Veltkamp (2004) in that they found shared representations in Spanish-English bilinguals living in an English speaking country for as little as two-months (and therefore being unlikely to be L2-dominant).

Even though the present results shed no light on whether or not the target constructions would surface in the subjects' productive use of either their second or first language, it does seem to indicate that L2 specific representations re-configure cognitive loads on subliminal processing. We think of the present results as representing empirical evidence of a key cognitive component of bilingual competence, namely, the growing capacity to process L2-specific input. It is this capacity that triggers the storage of items that can later be decomposed into productive, generalizable patterns.

Organon, Porto Alegre, nº 51, julho-dezembro, 2011, p. 103-128 


\section{6- CONCLUSION}

The results reported in this paper provide evidence that knowledge of a non-dominant $\mathrm{L} 2$ is active over the course of on-line sentence processing of a contrasting construction in relation to Brazilian Portuguese and English: the induced action predicate with verbs of manner-of-motion. These results suggest that the output of processing routines of bilinguals may be different from monolinguals' after a given proficiency threshold irrespective of the overall dominance profile of the bilingual individual. Our results may on the one hand imply that there is either a mismatch between perceptions of grammaticality and processing - which would then clearly indicate that judgments reflect levels of representations that are not directly involved with the construction of sentence representations at the very instant when the linguistic signal is processed. They may on the other hand imply that even bilinguals of a non-dominant L2 reconstruct their L1 representations altogether, a situation that would possibly lead to judgments that also differ from monolinguals'.

In the latter case there would be a situation of shared-grammar effects on processing that could also induce changes in linguistic generalizations. As suggested by Loebell and Bock (2003), an instance of processing-induced production and generalization would be priming, which would in turn be a crucial cognitive mechanism in two interrelated bilingualism and language contact situations: second language learning and also language change. Whereas Loebell and Bock's (2003) suggestion of the effect of shared grammars in second language learning is almost self-evident from the standpoint of the much emphasized role of input comprehension in second language acquisition, the possibility of similar effects on language change seems to be much less explored. However, we believe it to be a quite plausible corollary of second language learning, and we see the possibility of transformed language representations as a consequence of sustained and widespread bilingualism as a hypothesis much worthy of further investigation.

With respect to the findings of the present study, for example, it would be relevant to examine the extent to which the lower processing cost of Portuguese mimic run-verb induced action predicates by the bilingual subjects is related to parallel extension of acceptability of the construction as natural Portuguese usage. One could speculate that

Organon, Porto Alegre, nº 51, julho-dezembro, 2011, p. 103-128 
provided instances of this construction in Portuguese are processed by bilinguals and are also felt growingly more acceptable, and provided such bilinguals are participants of a linguistic domain where induced action predicates are frequent enough, they might start occurring naturally in their use of Portuguese, and ultimately gain validity among the larger community of speakers. Of course, these thoughts are in need of empirical evidence supporting existence the proposed mechanisms. We nevertheless believe that the data presented here suggests a niche for further explorations along these lines to take place.

\section{REFERENCES}

BOLAND, J. E.; TANEHAUS, M. K.; GARNSEY, S. M. \& CARLSON, G. N.. "Verb Argument Structure in Parsing Interpretation: Evidence from WH-Questions". Journal of Memory and Language. Vol. 34, 1995. pp.: 774-806.

CHOMSKY, N. Lectures on government and binding. Dordrecht: Foris, 1981.

CLIFTON, Jr. C.; TRAXLER, M. J.; MOHAMED, M. T.; WILLIAMS, H. S.; MORRIS, R. K.; RAYNER, K. "The use of thematic role information in parsing: Syntactic processing autonomy revisited". Journal of Memory and Language. Vol. 49, 2003. pp.: 317-334.

COOK, V. "Introduction: The changing L1 in the L2 user's mind". IN: COOK, V. (org.). Effects of the Second Language on the First. Bristol: Multiligual Matters, 2003. CULICOVER, P. Natural language syntax. Oxford: Oxford University Press, 2009.

DERWING, B. L. \& DE ALMEIDA, R. G. "Métodos experimentais em linguística”. In MAIA. M. \& FINGER, I. (orgs.), Processamento da Linguagem. Pelotas: Educat, 2005.

FERNÁNDEZ, E. Bilingual Sentence Processing - Relative Clause Attachment in English and Spanish. Amsterdam/Philadelphia: John Benjamins, 2003.

GOLDBERG, A. Constructions: A construction grammar approach to argument Structure. Chicago: University of Chicago Press, 1995.

GROSJEAN, F. Studying Bilinguals. New York: Oxford University Press, 2008. 
HARTSUIKER, R. J.; PICKERING, M.; VELTKAMP, E. "Is syntax separate or shared between languages? Cross-linguistic syntactic priming in Spanish- English bilinguals". Psychological Science. Vol. 15, 2004. p. 409-414. HERNÁNDEZ, A.; FERNÁNDES, E.; AZNAR-BESÉ, N.. “Bilingual sentence processing”. IN M. G. Gaskel (org.), The Oxford Handbook of Psycholinguistics. New York: Oxford University Press, 2007. JACKENDOFF, R. Foundations of language. Oxford: Oxford University Press, 2002.

JUFFS, A. "Some Effects of First Language Argument Structure and Morphosyntax on Second Language Sentence Processing". Second Language Research. Vol. 14, 1998. pp.: 406-424.

KÖPKE, B.; SCHMID, M. "Language attrition: the next phase". IN: SCHMID, M.; KÖPKE, B.; KEIJZER, M.; WEILEMAR, L. (orgs.). First Language Attrition: Interdisciplinary Perspectives on Methodological Issues. Amsterdam/Philadelphia: John Benjamins Publishing Company, 2004.

LEVELT. W. Speaking: From intention to articulation. Cambridge/Massachusetts: The MIT Press, 1989.

LEVIN, B. English Verb Classes and Alternations: A Preliminary Investigation. Chicago: University of Chicago Press, 1993.

LOEBELL, H.; BOCK, K. "Structural priming across languages". Linguistics. Vol. 51, 2003. p. 791-824.

MANN, H.B.; WHITNEY, D.R. "On a test of whether one of two random variables is stochastically larger than the other". Annals of Mathematical Statistics, Vol. 18, 1947. pp. 50-60.

MITCHELL, D. C. "On-line Methods in Language Processing: Introduction and Historical Review". IN: CARREIRAS, M. \& CLIFTON JR., C. (orgs.) The On-line Study of Sentence Comprehension. New York/Hove: Psychology Press, 2004.

MONTRUL, S. "Agentive Verbs of Manner and Motion in Spanish and English as Second Languages". Studies in Second Language Acquisition. Vol. 23, 2001. pp.: 171-206.

MONTRUL, S. "The L2 Acquisition of Dative Experiencer Subjects". Second Language Research. Vol. 14, 1998. pp.: 27-61.

NATION, P. Teaching and Learning Vocabulary. Boston, MA: Heinle \& Heinle, 1990.

Organon, Porto Alegre, nº 51, julho-dezembro, 2011, p. 103-128 
PAVLENKO, A.; JARVIS, S.. "Bidirectional transfer". Applied Linguistics. Vol. 23, 2002. pp. 190-214.

SILVA, Y. As Causativas Sintéticas no Português do Brasil: Novas Evidências a Favor da Estrutura Bipartida do VP. Unpublished Masters' Thesis. Belo Horizonte: Universidade Federal de Minas Gerais, 2009. SOUZA, R. A. "Argument Structure in L2 Acquisition: Language Transfer Re-visited in a Syntax and Semantics Perspective". Revista Ilha do Desterro - A Journal of English Language, Literatures in English and Cultural Studies. (Forthcoming in 2011).

STEPHENS, M. A. "EDF Statistics for Goodness of Fit and Some Comparisons". Journal of the American Statistical Association, Vol. 69, 1974. pp. 730-737.

TRUESWELL, J. C.; TANEHAUS, M. K. \& GARNSEY, S. M. "Semantic Influences on Parsing: Use of Thematic Role Information in Syntactic Ambiguity Resolution". Journal of Memory and Language. Vol. 33, 1994. pp.: 285-318.

VAN VALIN, R; LAPOLLA, R. Syntax: Structure, meaning, and function. Cambridge: Cambridge University Press, 1997.

WANG, Y.Y. "Probabilities of the Type I Errors of the Welch Tests for the Behrens-Fisher Problem". Journal of the American Statistical Association, Vol. 66, 1971. pp. 605-608.

WHITE, L. Second Language Acquisition and Universal Grammar. Cambridge: Cambridge University Press, 2003.

WILCOXON, F. "Individual comparisons by ranking methods". Biometrics, Vol. 1, 1945. pp. 80-83. 